\section{Respiratory epidemiology}

\section{S123 EXACERBATION RISK AND CHARACTERISATION OF THE UK'S ASTHMA POPULATION, FROM INFANCY TO OLD AGE}

${ }^{1} \mathrm{Cl}$ Bloom, ${ }^{2} \mathrm{~F}$ Nissen, ${ }^{2}$ Douglas, ${ }^{2} \mathrm{~L}$ Smeeth, ${ }^{1} \mathrm{P}$ Cullinan, ${ }^{1} \mathrm{JK}$ Quint. ${ }^{1} / \mathrm{mperial}$ College London, London, UK; ' London School of Hygiene and Tropical Medicine, London, UK

10.1136/thoraxjnl-2017-210983.129

Introduction and Objectives Few studies have examined the characteristics of a general asthma population; most have focussed on more severe patients or severe exacerbations. We sought to provide the first description of the UK's general asthma population.

Methods Population-based cohort study, April 2007 to September 2015, using linked primary and secondary care electronic healthcare records (Clinical Practice Research Datalink, Hospital Episode Statistics). Four age cohorts: 'Under $5 \mathrm{~s}$ ', '5 to 17 s', '18 to 54 s', '55+', are described. Exacerbation risk factors, including asthma severity (measured by the 2016 BTS stepwise approach), were assessed using random effects Poisson regression.

Results 424326 patients with current asthma were eligible ( $\mathrm{N}$, median follow-up: 'Under $5 \mathrm{~s}$ ' $=17,320,1$ year; ' 5 to $17 \mathrm{~s}$ ' $=82,707,3.3$ years; ' 18 to $54 \mathrm{~s}$ ' $=210,724,4$ years; '55 $+^{\prime}=113,575,5.1$ years). Over $60 \%$ of the total study population had mild asthma (BTS steps 1/2). There were differences between the cohort's characteristics, including by gender, disease severity and exacerbation pattern. The oldest cohort had the highest proportion, and the ' $5-17$ s' the lowest, on BTS step 3 or higher (figure 1). In the ' $55+$ ' cohort, $23 \%$ also had a diagnosis of COPD. Of the patients who exacerbated, the youngest cohort had the highest proportion of patients that exacerbated more than once a year ('Under $5 \mathrm{~s}$ ' $=54.7 \%$, ' 5 to $17 \mathrm{~s}$ ' $=13.1 \%$, ' 18 to $54 \mathrm{~s}$ ' $=18.8 \%$, ' $55+$ ' $=34.1 \%)$. The rate of any exacerbations was highest in the oldest cohort and lowest in the ' 5 to $17 \mathrm{~s}$ ' cohort (rate per 10 person-years, (95\% CI), 'Under $5 \mathrm{~s}$ ' $=4.27(4.18-4.38)$, '5 to $17 \mathrm{~s}$ ' $=1.48$ $(1.47-1.50), \quad$ ' 18 to $54 \mathrm{~s}^{\prime}=3.22 \quad(3.21-3.24), \quad$ ' $55+$ ' $=9.40$ (9.37-9.42)). In all cohorts, exacerbation rates increased with increasing asthma severity, after adjusting for potential confounders including gender, socioeconomic status, smoking, BMI, atopy, rhinitis, gastroesophageal reflux, anxiety, depression and COPD.

Conclusions This is the first descriptive study of the UK's general asthma population. The majority of UK asthma patients had mild disease, and did not exacerbate during follow-up. Patients aged $\geq 55$ years had the lowest proportion with mild asthma and the highest rate of exacerbations; the opposite was found in patients aged between 5 to 17 years. Increasing BTS step was significantly associated with increasing exacerbation rates across all generations.

\section{S124 TRENDS IN MORTALITY FROM IDIOPATHIC PULMONARY FIBROSIS IN THE EUROPEAN UNION: AN OBSERVATIONAL STUDY OF THE WHO MORTALITY DATABASE FROM 2001 - 2013}

${ }^{1} \mathrm{DC}$ Marshall, ${ }^{2} \mathrm{DD}$ Salciccioli, ${ }^{3} \mathrm{BS}$ Shea, ${ }^{4} \mathrm{P}$ Akuthota. 'University of Oxford, Oxford, UK; ${ }^{2}$ Mount Auburn Hospital, Cambridge, US; ${ }^{3}$ Alpert Medical School of Brown University, Providence, US; ${ }^{4}$ University of California San Diego, La Jolla, US

\subsection{6/thoraxjnl-2017-210983.130}

Background Idiopathic pulmonary fibrosis (IPF) is the most common of the idiopathic interstitial pneumonias and is characterised by progressive accumulation of scar tissue in the lungs. It carries a poor prognosis, with a median survival of only approximately 3 years after diagnosis. No previous reports have attempted to describe trends in IPF mortality across the European Union (EU).

Methods Country-level data for IPF mortality, identified in the WHO mortality database using ICD-10 codes for the period 2001-2013. Joinpoint analysis was performed to describe trends throughout the observation period.

Findings Median mortality was 3.75/1 00000 (IQR, 1.375.30) and 1.50/1 00000 (IQR, 0.65-2.02) for males and females, respectively. IPF mortality increased in the majority of the EU countries with the exceptions of Denmark, Croatia, Austria and Romania. There was a significant disparity in rates across Europe ranging from 0.41-12.1/100 000 for men and 0.24-5.63/100 000 for women. Most notable increases were

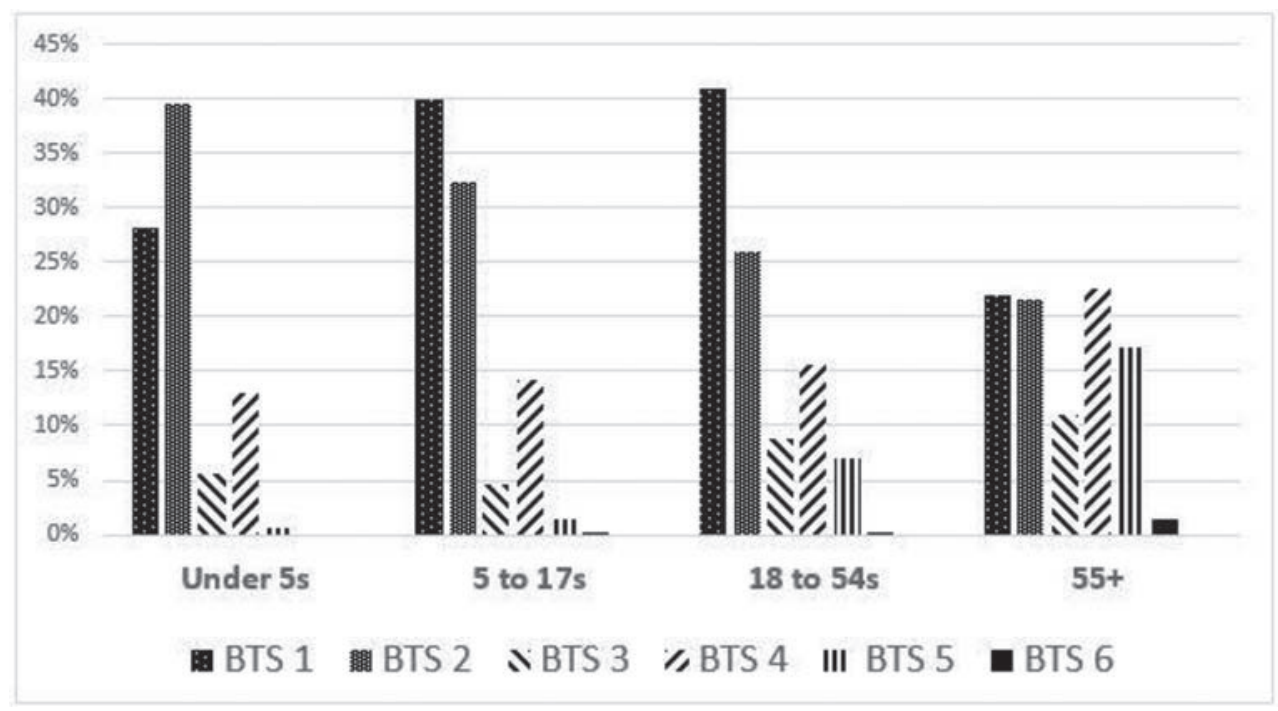

Abstact S123 Figure 1 Proportion of asthma patients in each BTS step by age cohort. 